\title{
Bicentenário da imprensa desafia sociedade a promover inclusão cognitiva
}

José Marques de Melo Professor emérito da Universidade de São Paulo é, atualmente, Diretor da Cátedra UNESCO de Comunicação da Universidade Metodista de São Paulo. Fundador e presidente da Rede Alfredo de Carvalho. E-mail: marquesmelo@uol.com.br

Resumo: O bicentenário da imprensa motiva perplexidades sobre o seu reduzido alcance na sociedade brasileira. Para romper o estado de exclusão cognitiva para o qual a imprensa elitista contribui, o autor resgata a trajetória da Rede Alfredo de Carvalho, focalizando seu compromisso com a democratização da mídia impressa.

Palavras-chave: midiologia, imprensa, história, Alfredo de Carvalho, Brasil.
Abstract: Print press bicentennial celebration is the starting point to issue the Brazilian society exclusion question in the field of mass media audience. In order to face this social gap created by illiteracy and stressed by elite press, the author rescue the trajectory of Alfredo de Carvalho Network, focusing its compromise with print media democratization.

Keywords: media studies, print press, history, Alfredo de Carvalho, Brazil.

O Brasil está comemorando o bicentenário da chegada da Corte de Dom João VI, episódio histórico que nos retirou da condição de colônia periférica e trouxe uma série de inovações a nossa sociedade, inclusive o funcionamento da imprensa.

Retardada em decorrência de fatores socioculturais que a inibiram, inviabilizaram ou manietaram, a imprensa periódica aqui se instalou de forma paradoxal. Circulou clandestinamente (transportada em porões de navios) ou apareceu oficialmente (arrolhada pela censura régia).

Mesmo depois de conquistar a liberdade, na esteira dos acontecimentos que nos conduziriam à independência política, a imprensa brasileira permaneceu como privilégio das elites letradas. Em pleno século XXI, somente 1 em cada 20 cidadãos desfruta o sabor da leitura do jornal diário.

Romper esse apartheid cognitivo foi justamente a finalidade da Rede Alfredo de Carvalho, criada como uma espécie de mutirão intelectual que pretende estabelecer nexos entre a era gutenberguiana e a idade digital. 


$$
\text { comunicação \& educação • Ano XIII • Número } 3 \text { • set/dez } 2008
$$

Constituída para sensibilizar a sociedade brasileira em relação ao papel que a imprensa pode desempenhar como fator civilizatório, a iniciativa convergiu naturalmente para a formação de um organismo sintonizado com o espírito do tempo.

\section{CONTEXTO}

A proposta cultural da Rede Alcar foi a celebração do bicentenário da implantação da imprensa no Brasil. Mas sua aspiração política é, na verdade, a conscientização nacional em torno da exclusão cultural.

Está justamente aí o diferencial entre a nossa cruzada e a iniciativa liderada pelo nosso patrono, há um século.

A idéia de Alfredo de Carvalho, acolhida pelo Instituto Histórico e Geográfico Brasileiro - IHGB, se transformou em projeto respaldado pelo governo nacional, gerando uma exposição jornalística, aberta ao público, na capital republicana e em outros estados da federação brasileira, em 1908.

Infelizmente, os catálogos referentes às regiões situadas ao sul do território nacional, tendo como divisor geopolítico a Bahia, desapareceram em função do incêndio que, naquela ocasião, destruiu preciosos originais depositados nos prelos da Imprensa Nacional. Esse fato sinaliza a maldição que se projetaria sobre a memória da nossa imprensa, penalizada pela incúria institucional e desprezada pelas nossas vanguardas intelectuais.

O descaso em relação à memória da imprensa traduz em certo sentido a atitude pátria referente à própria memória nacional, principalmente no âmbito da cultura não-erudita, condenando ao esquecimento as instituições e os personagens que fizeram história. Tanto assim que as novas gerações de profissionais midiáticos - jornalistas, publicitários, radialistas ou teledifusores -, formados pelas nossas universidades, possuem escasso conhecimento sobre a trajetória midiática brasileira.

Foi precisamente com a intenção de neutralizar essa lacuna cognitiva que tomamos a iniciativa de encetar um novo movimento cultural, buscando ao mesmo tempo preservar a memória da imprensa e construir a história midiática nacional. Nossa meta é desenvolver ações voluntárias e independentes, embora metodologicamente articuladas, no sentido de completar o inventário desencadeado há um século e ao mesmo tempo tecer a malha que dá sentido ao complexo midiático brasileiro.

A adesão de instituições publicamente legitimadas, como o Instituto Histórico e Geográfico Brasileiro - IHGB, a Academia Brasileira de Letras - ABL, a Sociedade Brasileira de Estudos Interdisciplinares da Comunicação - INTERCOM, além da Associação Brasileira de Imprensa - ABI, significou o fortalecimento da Rede Alcar e sua projeção em todo o território nacional.

Esse reconhecimento institucional completou-se com a participação da Imprensa Oficial do Estado de São Paulo, que assumiu o compromisso de editar 
os 4 volumes da série "Imprensa Brasileira: Personagens que fizeram História", em parceria com a Editora da Universidade Metodista de São Paulo.

Nesse projeto está implícita a ambição de motivar jovens pesquisadores para retomar as hipóteses e os roteiros esboçados, dando continuidade ao plano fundamental de construir a História Midiática Brasileira. Trata-se de resgatar os dois séculos já palmilhados e, ao mesmo tempo, iluminar as ações a serem empreendidas nesta conjuntura em que alimentamos a utopia de fincar a bandeira nacional no novo mapa do mundo.

De 13 a 16 de maio deste ano, no campus da Universidade Federal Fluminense, em Niterói, a Rede fez um balanço do acervo de conhecimentos até agora acumulados e também aprovou o estatuto que a transforma em sociedade civil, criando condições para sua institucionalização.

\section{SUJEITO}

Alfredo de Carvalho é o historiador brasileiro que se dedicou à preservação da memória da imprensa nacional, assumindo a liderança do grupo que catalogou todos os jornais e revistas publicados no Brasil, no período de 1808-1908. Desde então, nenhuma iniciativa foi realizada em nosso país para dar continuidade a esse inventário emblemático, com exceção de atos isolados e pessoais.

Pertencente à aristocracia pernambucana, Alfredo Ferreira de Carvalho nasceu em 27 de junho de 1870, na cidade do Recife, onde teve sua educação básica, inclusive o aprendizado de línguas estrangeiras.

Tornou-se poliglota, adquirindo fluência em alemão, inglês, holandês, francês, italiano e espanhol. Isso o habilitou a realizar os estudos superiores no exterior, na área de engenharia, inicialmente em Hamburgo, Alemanha, e finalmente em Philadelphia, Estados Unidos da América.

Muito jovem, enveredou pela carreira militar, abandonada em função do seu envolvimento na revolta da fortaleza de Santa Cruz, no Rio de Janeiro. Diplomado, trabalhou como engenheiro nas ferrovias Central do Brasil e Central de Pernambuco.

Tentou ingressar no magistério, prestando concurso para o Ginásio Pernambucano; classificado em primeiro lugar, frustrou-se com a anulação do resultado.

Decidiu, então, fazer excursões pelo país; mas adoeceu, no Amazonas, retornando a Pernambuco.

Chegou a trabalhar como engenheiro fiscal de usinas de açúcar, embora seus esforços estivessem voltados para as atividades intelectuais, principalmente o jornalismo.

Faleceu precocemente, em 1916, enfrentando situação de penúria, privações e debilidade, após exaurir-se o legado patrimonial investido na aquisição de uma valiosa biblioteca de obras raras sobre o Brasil. 
comunicação \& educação • Ano XIII • Número 3 • set/dez 2008

\section{AÇÃO}

Depois de percorrer os principais centros do mundo ocidental e de excursionar pelo seu país, Alfredo de Carvalho recolheu-se à pacata vida provinciana, tendo participação ativa na dinâmica intelectual de Pernambuco.

Sua principal tribuna foi a imprensa, publicando regularmente artigos, ensaios e comentários, sobretudo no Jornal do Recife e Diário de Pernambuco, bem como em revistas acadêmicas.

Perfilou adequadamente o papel de intelectual orgânico da aristocracia regional, participando da geração que restaurou o sentimento de pernambucanidade. A esse contingente pertenceram figuras emblemáticas como José Higino Duarte Pereira e Francisco Augusto Pereira da Costa, a quem sucedeu na liderança institucional, presidindo a Academia Pernambucana de Letras e o Instituto Arqueológico, Histórico e Geográfico de Pernambuco.

Mesmo vivendo na província, nunca assumiu a condição de literato provinciano, isolando-se do país e do mundo. Ao contrário, manteve-se sintonizado com a vanguarda do seu tempo, associando-se a entidades como o Instituto Histórico e Geográfico Brasileiro (Rio de Janeiro) e a Antropological Society (Washington).

Sua obra contém livros valiosos para a compreensão da singularidade pernambucana, como Frases e palavras: problemas histórico-etimológicos (1906) e Estudos Pernambucanos (1907), mas também para o entendimento do éthos brasileiro, como O tupi na corografia pernambucana: elucidário etimológico (1907), a Biblioteca Exótico-Brasileira (1929) e Aventuras e aventureiros no Brasil (1930).

Se a natureza do seu trabalho como intérprete da sociedade brasileira causava polêmica, num ponto ele suscita unanimidade. "Alfredo de Carvalho é hoje porventura o brasileiro que melhor conhece a história da imprensa no Brasil", afirmava em alto e bom som o crítico literário José Veríssimo.

É autor, nesse campo, das seguintes obras: Jornais pernambucanos, 1831-98 (1899); A imprensa baiana, $1811-98$ (1899); Diário de Pernambuco, 1825-1908 (1908); Anais da imprensa periódica pernambucana de 1821 a 1908 (1908).

Contudo, sua grande contribuição à história da imprensa brasileira se dá em dois momentos distintos. Como pesquisador, ele desvenda a hipótese lendária da tipografia holandesa do século XVII. E como líder intelectual, comanda o mutirão que faz o inventário da imprensa brasileira no século XIX.

Um século depois, esse projeto arrojado inspirou a constituição de uma rede de pesquisa que adotou seu artífice como patrono.

A Rede Alfredo de Carvalho pretende estabelecer nexos entre as galáxias de McLuhan e de Bill Gates. Instituição ancorada em sua época, mas antenada no porvir, ela tem-se robustecido e dinamizado à medida que se torna capaz de otimizar as oportunidades típicas da emergente sociedade digital. Dessa maneira, conquista adesões e projeta-se no cenário contemporâneo, acalentando utopias.

1. VERISSIMO, José. Um estudioso pernambucano. Rio de Janeiro: Kosmos, 1907. p. 122.
Está justamente aí o diferencial entre a nossa cruzada e a iniciativa liderada pelo nosso patrono, há um século. 


\section{MEMÓRIA}

Há quase cem anos, portanto, o Brasil testemunhava a iniciativa emblemática no sentido de resgatar a memória da nossa imprensa.

O historiador pernambucano Alfredo de Carvalho, que, no anoitecer do século XIX, havia feito pesquisas essenciais para desvendar enigmas persistentes no itinerário da mídia impressa brasileira, propõe-se, na alvorada do século XX, a inventariar o panorama dos jornais e revistas publicados no País, durante o primeiro século da sua vigência em território nacional.

Acolhida pelo IHGB - Instituto Histórico e Geográfico Brasileiro, a idéia se transforma em projeto respaldado pelo governo nacional, gerando uma exposição jornalística, aberta ao público, na capital republicana e em outros estados da federação brasileira, em 1908. A comunicação desse projeto foi efetuada aos sócios do IHGB pelo secretário perpétuo, em sessão realizada na $13^{\text {a }}$ sessão ordinária da instituição, no dia 29 de julho de $1907^{2}$.

Como resultado desse esforço incomensurável, do qual participaram ilustres historiadores e hemerógrafos de várias províncias, são editados dois volumes da Revista do IHGB, reproduzindo os catálogos elaborados pelos pesquisadores estaduais das regiões Norte-Nordeste, bem como o ensaio monográfico escrito magnificamente por Alfredo de Carvalho ${ }^{3}$.

Não fosse a ação preservacionista da Biblioteca Nacional e de algumas Bibliotecas Estaduais/Municipais ou a dedicação laboriosa de alguns colecionadores particulares, o itinerário percorrido pela nossa imprensa no século XX teria sido apagado definitivamente da memória brasileira. Todo esse acervo mapeado foi microfilmado graças à cruzada documental liderada quixotescamente por Esther Bertoletti ${ }^{4}$, que acalenta o sonho de ver instalado em nosso país uma Hemeroteca Nacional, a exemplo do que ocorre em outros países europeus ou americanos.

O desconhecimento sobre a história da mídia pelos novos profissionais da área os transforma em reféns involuntários dos gêneros e formatos alienígenas, reproduzindo continuamente modelos oriundos das matrizes geradoras da cultura pós-moderna, quase sempre descolados da nossa realidade. Trata-se de fenômeno determinado pela ignorância em relação aos padrões midiáticos já testados em território nacional, ausentes das lições que tiveram dos seus mestres, tanto na academia quanto na indústria.

Foi precisamente com a intenção de neutralizar essa lacuna cognitiva que tomamos a iniciativa de encetar um novo movimento cultural, buscando ao mesmo tempo preservar a memória da imprensa e construir a história midiática nacional ${ }^{5}$.

\section{PERFIL}

A Rede Alfredo de Carvalho para o Resgate da Memória da Imprensa e para a Construção da História da Mídia no Brasil - Rede Alcar - é uma organização não-governamental. Fundada no dia 5 de abril de 2001, na cidade do
2. FLEUISS, Max. Apresentação. Revista do Instituto Histórico e Geográfico Brasileiro. Tomo consagrado à Exposição Comemorativa do Primeiro Centenário da Imprensa Periódica no Brasil. Rio de Janeiro, 1908. p. V-XIII, tomo I.

3. CARVALHO, Alfredo de. Gênese e progressos da imprensa periódica no Brasil. Revista do Instituto Histórico e Geográfico Brasileiro. Tomo consagrado à Exposição Comemorativa do Primeiro Centenário da Imprensa Periódica no Brasil. Rio de Janeiro, 1908. p. 1-89, tomo I.

4. BERTOLETTI, Esther. Nota prévia: periódicos brasileiros em microforma. Catálogo Coletivo. Rio de Janeiro, Biblioteca Nacional, 1985. p. 13-16.

5. MARQUES DE MELO, José. O pragmatismo utópico da Rede Alfredo de Carvalho. In: PONTES TAVARES, Luis Guilherme (Org.). Rumo ao bicentenário da imprensa brasileira. Salvador: NEHIB/Editora da UFBA, 2002. p. 9-32. 
comunicação \& educação • Ano XIII • Número 3 • set/dez 2008

Rio de Janeiro, sua finalidade é contribuir para a democratização do sistema midiático nacional, preparando a celebração do Bicentenário da Imprensa Brasileira (1808-2008).

A iniciativa foi tomada pela Cátedra UNESCO de Comunicação da Universidade Metodista de São Paulo, que imediatamente conquistou a adesão da Cátedra FENAJ de Jornalismo da Universidade Federal de Santa Catarina. Logo em seguida, foram estabelecidas parcerias institucionais com a Sociedade Brasileira de Estudos Interdisciplinares da Comunicação - INTERCOM, a Associação Brasileira de Imprensa - ABI e o Instituto Histórico e Geográfico Brasileiro - IHGB.

A estrutura de rede tem permitido o seu funcionamento dinâmico, assegurando liberdade de iniciativa aos organismos que reúne e promovendo inúmeras atividades, coordenadas de modo pluralista por um comitê nacional.

Integrados por pesquisadores de diferentes partes do território brasileiro, Grupos Temáticos se articulam em torno dos segmentos que povoam a complexa estrutura do nosso sistema midiático.

Suas atividades têm sido concretizadas através de Congressos Nacionais, realizados anualmente em diferentes partes do território nacional, e de Seminários Regionais, organizados ocasionalmente, por iniciativa de instituições públicas ou privadas.

Neste primeiro quinquênio de mutirão intelectual, já acumulamos um acervo de 745 monografias sobre a História das Indústrias Midiáticas no Brasil, como se vê no quadro I.

QUADRO I - Rede Alcar. Quadro comparativo das pesquisas realizadas

\begin{tabular}{|l|c|c|c|c|c|c|c|}
\hline Grupos Temáticos & 2003 & 2004 & 2005 & 2006 & 2007 & 2008 & Total \\
\hline História do JORNALISMO & 12 & 26 & 39 & 69 & 44 & 99 & 289 \\
\hline História da PROPAGANDA & 15 & 14 & 18 & 14 & 19 & 43 & 123 \\
\hline História das RELAÇÕES PÚBLICAS & 1 & 8 & 12 & 8 & 4 & 11 & 44 \\
\hline História da MÍDIA IMPRESSA & 8 & 16 & 21 & 21 & 10 & 39 & 115 \\
\hline História da MÍDIA VISUAL & 8 & 7 & 6 & 7 & 4 & 26 & 58 \\
\hline História da MÍDIA AUDIOVISUAL & 13 & 10 & 15 & 21 & 18 & 57 & 134 \\
\hline História da MÍDIA SONORA & 5 & 22 & 30 & 22 & 24 & 49 & 152 \\
\hline História da MÍDIA DIGITAL & 1 & 6 & 13 & 8 & 11 & 29 & 68 \\
\hline História da MÍDIA ALTERNATIVA & 1 & 1 & 10 & 16 & 11 & 32 & 71 \\
\hline História da MIDIOLOGIA & 1 & 3 & 17 & 12 & 12 & 21 & 66 \\
\hline Mostra Documental HIMIDIA & 0 & 0 & 0 & 32 & $?$ & - & 32 \\
\hline TOTAL & 65 & 113 & 181 & 230 & 157 & 406 & 1152 \\
\hline
\end{tabular}

Livros ou coletâneas vêm sendo igualmente publicados, em parceria com editoras universitárias ou organismos de interesse público (Quadro II). 


\section{Quadro II - Rede Alcar. Publicações seriadas}

1. Cipriano Barata na Sentinela da Liberdade - Marco Morel, Salvador, Academia Baiana de Letras/Assembléia Legislativa do Estado da Bahia, 2001, 412 p.

2. Rumo ao Bicentenário da Imprensa Brasileira - José Marques de Melo, Cybelle de Ipanema e Esther Bertoletti, Salvador, NEHIB, 2002, 69 p.

3. Marco Zero da Rede Alfredo de Carvalho na Bahia - Luiz Guilherme Pontes Tavares (Ed.), Salvador, Núcleo de Estudo da História dos Impressos da Bahia, 2003, 43 p.

4. Vargas, agosto de 54, a história contada pelas ondas do rádio - Ana Baum (Org.), Rio de Janeiro, Editora Garamond, 2004, 237 p.

5. São Paulo na Idade Mídia - José Marques de Melo e Antonio Adami (Orgs.), São Paulo, Arte \& Ciência, 2004, 377 p.

6. Apontamentos para a história da Imprensa na Bahia - Luis Guilherme Pontes Tavares (Org.), Salvador, Academia Baiana de Letras/Assembléia Legislativa do Estado da Bahia, 2005, 157 p.

7. Propaganda: história e modernidade - Adolpho Queiroz (Org.), São Paulo, Rede Alcar, 2005, 303 p.

8. Zilá Moreira: a repórter do Estadão na Bahia, no tempo da Ditadura Militar - Luis Guilherme Pontes Tavares (Org.), Salvador, NEHIB, 2005, 31 p.

9. A primeira Gazeta da Bahia: Idade D'Ouro do Brasil - Salvador, Edufba, 2005.

10. Imprensa brasileira: personagens que fizeram história, vol. 1 - José Marques de Melo (Org.), São Paulo, IMESP, 2005.

11. Nome para compor em caixa alta: Artur Arezio da Fonseca - Luis Guilherme Pontes Tavares, Salvador, Assembléia Legislativa do Estado da Bahia, 2005.

12. Imprensa brasileira: personagens que fizeram história, vol. 2 - José Marques de Melo (Org.), São Paulo, IMESP, 2006.

13. Comunicação a serviço do cidadão - Rossana Gaia (Org.), Maceió, Instituto Zumbi dos Palmares, 2006

14. Sotaques regionais da propaganda - Adolpho Queiroz (Org.), São Paulo, Arte \& Ciência, 2006.

15. História e imprensa: representações culturais e práticas de poder - Lúcia Neves, Marco Morel e Tânia Ferreira (Orgs.), Rio de Janeiro, DPA Editora, 2006.

16. Síndrome da mordaça - José Marques de Melo (Org.), São Bernardo do Campo, Editora Metodista, 2007.

17. Anais da Imprensa da Bahia - 1 Centenário, 1811-1911 - Alfredo de Carvalho e João Nepomuceno Torres, Salvador, Instituto Histórico e Geográfico da Bahia, 2007.

18. Os Bandeirantes da Idade Mídia - José Marques de Melo (Org.), São Paulo, Angellara/Intercom, 2007.

19. História Cultural da Imprensa, Brasil - 1900-2000 - Marialva Barbosa, Rio de Janeiro, Maud, 2007.

20. Imprensa brasileira: personagens que fizeram história, vols. 3/4 - José Marques de Melo (Org.), São Paulo, IMESP, 2008.

\section{DESAFIO UTÓPICO}

Portanto, o ano de 2008 não é nossa meta de chegada, mas nosso ponto de partida. A utopia acalentada pela Rede Alfredo de Carvalho é a de pavimentar o caminho, neste início de século, para que a imprensa deixe de ser um privilégio das elites. 
comunicação \& educação • Ano XIII • Número 3 • set/dez 2008

Não é demasiado repetir que, nestes dois primeiros séculos de existência, a imprensa brasileira tem excluído ostensivamente os maiores contingentes da nossa população. Basta lembrar que, num país de 180 milhões de habitantes, os nossos jornais diários alcançam tiragens ridículas, hoje estimadas em 7 milhões de exemplares.

Uma nação constituída por habitantes que não sabem ler ou que têm fome de leitura e sede de cultura, está condenada historicamente a permanecer na periferia da chamada sociedade do conhecimento.

Superar essa situação vexatória depende não apenas do voluntarismo dos intelectuais, mas da adesão dos líderes empresariais e das vanguardas corporativas como forças motrizes capazes de mobilizar toda a sociedade.

\section{REFERÊNCIAS BIBLIOGRÁFICAS}

BERTOLETTI, Esther. Nota prévia: periódicos brasileiros em microforma. Catálogo Coletivo. Rio de Janeiro, Biblioteca Nacional, 1985.

CARVALHO, Alfredo de. Gênese e progressos da imprensa periódica no Brasil. Revista do Instituto Histórico e Geográfico Brasileiro. Tomo consagrado à Exposição Comemorativa do Primeiro Centenário da Imprensa Periódica no Brasil. Rio de Janeiro, 1908. tomo I.

FLEUISS, Max. Apresentação. Revista do Instituto Histórico e Geográfico Brasileiro. Tomo consagrado à Exposição Comemorativa do Primeiro Centenário da Imprensa Periódica no Brasil. Rio de Janeiro, 1908. tomo I.

MARQUES DE MELO, José. O pragmatismo utópico da Rede Alfredo de Carvalho. In: PONTES TAVARES, Luis Guilherme (Org.). Rumo ao bicentenário da imprensa brasileira. Salvador: NEHIB/Editora da UFBA, 2002.

VERÍSSIMO, José. Um estudioso pernambucano. Rio de Janeiro: Kosmos, 1907. 